\title{
American Lung Association
}

National Cancer Institute

\section{Source}

National Cancer Institute. American Lung Association. NCI Thesaurus. Code C39316.

The American Lung Association is a voluntary national health org anization funded by contributions from the public, along with gifts and grants from corporations, foundations and government agencies, and dedicated to fight against lung diseases with special emphasis on asthma, tobacco control and environmental health. The Association supports basic and clinical research through training and 'seed' grants for researchers who are at the early stage of their careers. 